\title{
Diagnostic and mortality outcomes in a cohort of adult meningitis suspects in KwaZulu-Natal
}

\author{
Onke Nonkala ${ }^{a}$, Colleen Aldous ${ }^{b}$ and Douglas Wilson ${ }^{a}$ \\ ${ }^{a}$ Department of Internal Medicine, Edendale Hospital, Pietermaritzburg, University of KwaZulu-Natal, Durban, South Africa

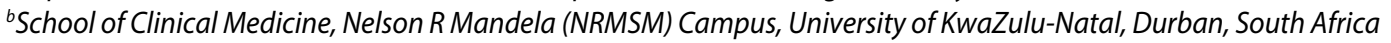

Background: The clinical value of lumbar puncture (LP) in settings with a high human immunodeficiency virus (HIV) prevalence has not been well defined.

Methods: We performed a retrospective chart review in 394 adults undergoing LP at a single regional level public-sector hospital in KwaZulu-Natal, South Africa.

Results: The median age of all the participants was 32.8 years (interquartile range 26.7;41.2). Two hundred and fifty-five participants (64.7\%) had an abnormal cerebrospinal fluid (CSF) analysis; 202 (79.5\%) of whom were HIV seropositive. Sixty-four (25.1\%) were diagnosed with tuberculosis meningitis and $62(24.3 \%)$ tested positive for cryptococcal antigen. Thirty-three specimens grew Cryptococcus neoformans (32 tested antigen positive) and Streptococcus pneumonia was isolated in three specimens (0.8\%). An abnormal CSF result was associated with increased risk of inpatient death (OR $3.8[95 \% \mathrm{Cl} 1.7 ; 9.6]$; $p$-value $=0.0004)$

Conclusions: CSF abnormalities were common in this cohort of adults with suspected meningitis in KwaZulu-Natal, and were associated with increased odds of mortality in hospitalised participants.

Keywords: adult, cryptococcus, HIV, Meningitis, mortality, tuberculosis

\section{Introduction}

Meningitis is the most common central nervous system infection in adults and is associated with significant morbidity. ${ }^{1-4}$ In subSaharan Africa, the human immunodeficiency virus (HIV) pandemic increased the risk of meningitis in seropositive adults, with Cryptococcus neoformans and Mycobacterium tuberculosis emerging as prominent pathogens. ${ }^{5-8}$ Symptoms of meningitis include headache, fever, altered mental status and neck stiffness, but are non-specific. ${ }^{9}$ Clinicians working in high HIV prevalence settings need to maintain a high level of suspicion for meningitis, and investigate when the presenting symptoms suggest the diagnosis.

The diagnosis of meningitis is dependent on laboratory analysis of cerebrospinal fluid (CSF), obtained during lumbar puncture (LP). This invasive procedure carries a small risk of adverse outcomes such as post-lumbar puncture headache, iatrogenic infection and bleeding. ${ }^{10-12}$ Clinicians therefore need to weigh the risk of adverse outcomes following LP against the possibility of diagnosing a potentially fatal case of meningitis. The South African province of KwaZulu-Natal has the highest HIV prevalence in South Africa, with $17.4 \%$ of adults estimated to be HIV seropositive; ${ }^{13}$ however, the diagnostic outcomes after LP have not been well characterised in this setting. A descriptive retrospective chart review was therefore undertaken in patients undergoing LP in the medical admissions service at Edendale Hospital, a 900-bed public sector institution in the Umgungundlovu district of KwaZulu-Natal.

\section{Methods}

The names and medical record identifiers were collected for all patients older than 13 years and registered for CSF analysis at the National Health Laboratory at Edendale Hospital during the period 01 February 2013 to 31 December 2013. Medical records for these patients were requested from the medical registry; records that were not obtained were searched for again on two further occasions and then classified as irretrievable if not found. Medical information was extracted by one researcher (ON), captured into a standardised data form and transferred into an Epidata file (Version 3.1, Odense Denmark, EpiData Association, 2000-2008). Information included demographic details, clinical features that led to LP, the results of CSF analysis, initial treatment, and clinical outcomes in the subset of participants who were admitted after LP.

An abnormal CSF analysis was defined as one or more of the following: lymphocyte count $\geq 5 \times 10^{9}$ cells/l, neutrophil count $\geq 1 \times 10^{9}$ cells $/$, protein $>0.45 \mathrm{~g} / \mathrm{l}$, and glucose $<2.2 \mathrm{mmol} / \mathrm{l}$. Severe CSF abnormality were defined as lymphocyte count $\geq 20 \times 10^{9} \mathrm{cells} / \mathrm{l}$, polymorph count $\geq 5 \times 10^{9}$ cells $/ \mathrm{l}$, protein $>1.0 \mathrm{~g} / \mathrm{l}$ and glucose $<2.2 \mathrm{mmol} / \mathrm{l}$. Participants with red blood cells in the CSF, but with all other parameters normal, were classified as having a traumatic tap. Results which could not be evaluated, defined as CSF analysis without a lymphocyte or neutrophil count, were excluded from further CSF analyses.

Ethical and regulatory approval was obtained from the Biomedical Research Ethics Committee of the University of KwaZulu-Natal and the KwaZulu-Natal Department of Health. Participant identifiers obtained during chart review were securely kept in a separate file, and were not entered into the electronic database.

Statistical analyses were performed using Analyse-it for Microsoft Excel Version 4.51 (๔ 1997-2016 Analyse-it Software Limited). Distributions of continuous data were determined using the Kolmogorov-Smirnov test, mean values were compared using the t-test, and median values compared using the WilcoxonMann-Whitney test. The proportions of categorical variables and odds ratios were calculated using the Fisher Exact test or Pearson Chi-squared test. 


\section{Results}

A total of 890 patients underwent LP during the study period and 394 medical records (44.2\%) were obtained and analysed. The demographic and clinical data of these participants are shown in Table 1. Headache, fever and confusional state were the most frequently reported symptoms. Almost $80 \%$ of participants undergoing LP were HIV seropositive, with men and women equally testing positive for HIV (odds ratio (OR) 1.0 [95\% confidence interval (Cl) $0.3 ; 3.5]$ ). Nine participants who underwent LP (2.3\%) had results which could not be evaluated and were excluded from further analyses. CSF results from 385 participants were evaluated. Two hundred and fifty-five participants $(66.2 \%)$ were determined to have an abnormal CSF result. Seventy-eight participants (20.3\%) had a normal CSF analysis, and a further 52 had a traumatic tap that was otherwise normal (13.5\%). The study profile by CSF category is shown in Figure 1.

\section{Associations with abnormal CSF analysis}

Associations between clinical and demographic parameters and abnormal CSF analysis are shown in Table 2. Participants with neck stiffness, vomiting and photophobia had significantly increased odds for CSF abnormality. Headache, fever or rigors, altered mental state (confusion), anaemia, renal impairment and positive HIV serology were not associated with CSF abnormality.

Median age was similar in the two groups: 32.8 (IQR 26.7; 41.2) years in the group with abnormal CSF, and 31.7 (IQR 26.1; 38.6) years in the group with normal CSF ( $p$-value $=0.1)$. One hundred and sixty-seven participants had a paired CD4 count and cryptococcal latex antigen test (CLAT): the median (IQR) CD4 count was $41(20 ; 79)$ cells/ $\mu$ in those with a positive CLAT result, and $189(60 ; 368)$ cells $/ \mu$ in those with a negative CLAT result $(p<0.0001)$.

\section{Clinical and laboratory features of participants with an abnormal CSF analysis}

The demographic, clinical and laboratory parameters of the 255 participants with abnormal CSF findings are shown in Table 3. Almost $80 \%$ of this group were HIV seropositive, with headache, neck stiffness and altered mental state as the most prominent clinical characteristics. An abnormal number of inflammatory

Table 1: Demographic and clinical data in all 394 participants.

\begin{tabular}{|l|c|}
\hline & $n(\%)$ \\
\hline Age $\left[n^{*}=381\right]$ median (IQR) years & $32.3(26.2 ; 40.2)$ \\
\hline Female $\left[n^{*}=317\right](\%)$ & $171(53.9)$ \\
\hline Known HIV seropositive (\%) & $240(60.9)$ \\
\hline Headache $\left[n^{*}=374\right](\%)$ & $226(60.4)$ \\
\hline Neck stiffness [ $\left.n^{*}=375\right](\%)$ & $170(45.3)$ \\
\hline Photophobia [ $n=371](\%)$ & $100(27)$ \\
\hline Fever $\left[n^{*}=370\right](\%)$ & $40(10.8)$ \\
\hline Delirium $\left[n^{*}=374\right](\%)$ & $140(37.4)$ \\
\hline Cranial nerve palsy [n* $\left.n^{*} 370\right](\%)$ & $24(0.65)$ \\
\hline Haemoglobin $\left[n=337^{*}\right]$ mean (SD) g/dl & $11.3(2.25)$ \\
\hline Creatinine [ $\left.n^{*}=344\right]$ median (IQR) micromol/I & $71(56 ; 94.6)$ \\
\hline ALT $\left[n^{*}=312\right]$ median (IQR) U/I & $26(17 ; 42)$ \\
\hline GGT $\left[n^{*}=303\right]$ median (IQR) U/I & $42(21.2 ; 98)$ \\
\hline Treated with ceftriaxone [ $\left.n^{*}=378\right](\%)$ & $345(87.6)$ \\
\hline
\end{tabular}

$n^{*}=$ Number of participants with information available in the medical record; $\mathrm{IQR}=$ interquartile range.

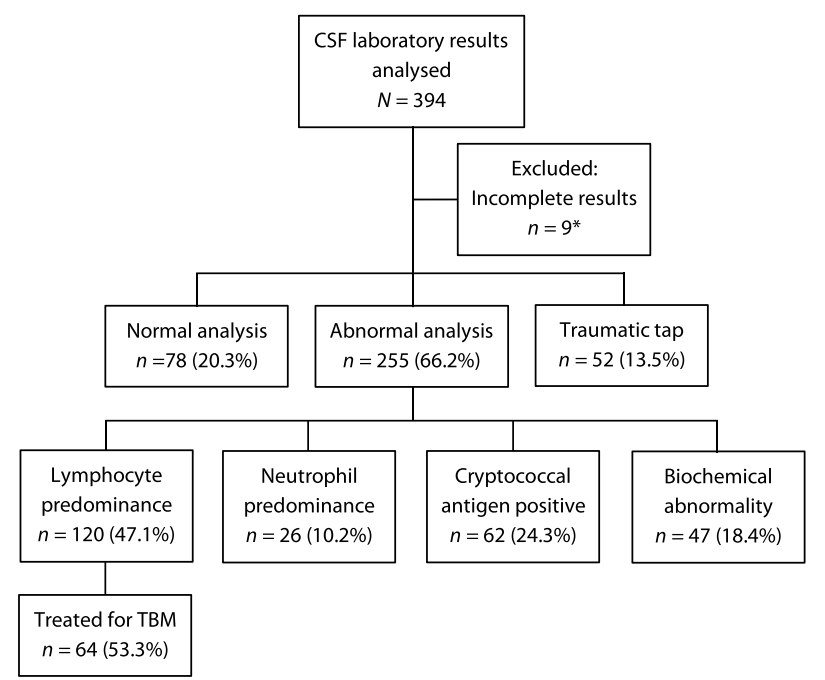

Note: *Missing lymphocyte or neutrophil count; TBM = tuberculosis meningitis.

Figure 1: Study profile.

Table 2: Clinical parameters associated with abnormal CSF analysis.

\begin{tabular}{|c|c|c|c|c|}
\hline & \multicolumn{2}{|c|}{ Excluding traumatic tap } & \multicolumn{2}{|c|}{ Including traumatic tap } \\
\hline & $\begin{array}{c}\text { Odds Ratio } \\
\text { (95\% CI) }\end{array}$ & $p$-value & $\begin{array}{l}\text { Odds Ratio } \\
\text { (95\% CI) }\end{array}$ & $p$-value \\
\hline Age (years) & $1.3(0.7 ; 2.3)$ & 0.4 & $1.4(0.9 ; 2.2)$ & 0.2 \\
\hline Female gender & $0.6(0.3 ; 1.4)$ & 0.1 & $0.75(0.4 ; 1.3)$ & 0.3 \\
\hline $\begin{array}{l}\text { Known HIV } \\
\text { seropositive }\end{array}$ & $0.9(0.1 ; 3.4)$ & 1.0 & $1.0(0.3 ; 3.0)$ & 1.0 \\
\hline Headache & $1.4(0.8 ; 2.5)$ & 0.2 & $1.5(0.9 ; 2.4)$ & 0.07 \\
\hline Neck stiffness & $2.1(1.2 ; 3.7)$ & 0.01 & $2.1(1.3 ; 3.5)$ & 0.0009 \\
\hline $\begin{array}{l}\text { Fever and/or } \\
\text { rigors }\end{array}$ & $0.8(0.4 ; 2.0)$ & 0.7 & $0.8(0.4 ; 1.7)$ & 0.6 \\
\hline Delirium & $1.6(0.9 ; 3.0)$ & 0.10 & $1.2(0.8 ; 2.0)$ & 0.4 \\
\hline Vomiting & $1.7(0.9 ; 3.4)$ & 0.08 & $1.9(1.1 ; 3.2)$ & 0.02 \\
\hline Photophobia & $3.0(1.4 ; 7.0)$ & 0.002 & $2.4(1.3 ; 4.3)$ & 0.002 \\
\hline $\begin{array}{l}\text { Haemoglobin < } \\
10 \mathrm{~g} / \mathrm{dl}\end{array}$ & $1.0(0.5 ; 2.0)$ & 1.0 & $1.0(0.6 ; 1.7)$ & 1.0 \\
\hline $\begin{array}{l}\text { Creatinine > } \\
150 \mu \mathrm{mol} / \mathrm{l}\end{array}$ & $1.5(0.5 ; 5.1)$ & 0.6 & $1.3(0.6 ; 3.5)$ & 0.6 \\
\hline $\mathrm{ALT}>50 \mathrm{IU}$ & $0.5(0.2 ; 1.0)$ & 0.03 & $0.5(0.3 ; 1.0)$ & 0.04 \\
\hline GGT > 50 IU & $1.0(0.5 ; 1.9)$ & 1.0 & $1.4(0.8 ; 2.3)$ & 0.2 \\
\hline
\end{tabular}

cells was found in 146 (57.2\%) participants, with 120 (82.2\%) having lymphocytic predominance, and 26 (17.8\%) with neutrophil predominance. An abnormal biochemical value (either protein or glucose) was found in 47 (18.4\%).

One hundred and fifty-two participants with abnormal CSF (59.6\%) had at least one severe CSF abnormality. The frequency of severe CSF abnormalities is shown in Figure 2. The majority of participants had only one severe abnormality, the most common of which were elevated protein $(n=96$ [38\%]), followed by lymphocytic predominance $(n=81$ [32\%]), reduced glucose level $(n=80[32 \%])$, and polymorph predominance $(n=50[20 \%])$.

Sixty-two participants (24.3\%) had a positive CSF cryptococcal antigen test, with the odds of an altered mental state being lower in this group of patients (OR $0.4[95 \% \mathrm{Cl} 0.2 ; 0.9], p=0.02$ ). 
Table 3: Clinical and laboratory features in 255 participants with abnormal CSF analysis.

\begin{tabular}{|c|c|}
\hline & $n(\%)$ \\
\hline Age $\left[n^{*}=253\right]$ median $(\mathrm{IQR})$ years & $32,8(26.7 ; 41.2]$ \\
\hline Female $\left[n^{*}=205\right](\%)$ & $98(47.8)$ \\
\hline Known HIV seropositive [ $\left.n^{*}=254\right](\%)$ & $202(79.5)$ \\
\hline CD4 count $[n=177]$, median (IQR) cells $/ \mu \mathrm{l}$ & $100(36 ; 319)$ \\
\hline Headache $\left[n^{*}=241\right](\%)$ & $156(64.7)$ \\
\hline Neck stiffness [ $\left.n^{*}=243\right](\%)$ & $126(51.9)$ \\
\hline Photophobia $\left[n^{*}=240\right](\%)$ & $79(32.9)$ \\
\hline Fever $\left[n^{*}=240\right](\%)$ & $24(10)$ \\
\hline Delirium [ $\left.n^{*}=243\right](\%)$ & $93(38.3)$ \\
\hline Cranial nerve palsy $\left[n^{*}=239\right](\%)$ & $20(0.84)$ \\
\hline Lymphocyte cell count $\left[n^{*}=254\right]$ median $(\mathrm{IQR}) \times 10^{9}$ cells $/ \mathrm{l}$ & $7(0.0 ; 29)$ \\
\hline Polymorph cell count $\left[n^{*}=254\right]$ median $(\mathrm{IQR}) \times 10^{9}$ cells $/ \mathrm{l}$ & $0(0.0 ; 3)$ \\
\hline Protein $\left[n^{*}=253\right]$ median (IQR) $\mathrm{g} / \mathrm{l}$ & $0.7(0.5 ; 1.6)$ \\
\hline Glucose $\left[n^{*}=249\right]$ median $(\mathrm{IQR}) \mathrm{mmol} / \mathrm{l}$ & $2.6(2.0 ; 3.2)$ \\
\hline Cryptococcal antigen positive $\left[n^{*}=242\right](\%)$ & $62(25.6)$ \\
\hline Haemoglobin $\left[n=337^{*}\right]$ mean (SD) $\mathrm{g} / \mathrm{dl}$ & $11.2(2.6)$ \\
\hline Creatinine $\left[n^{*}=344\right]$ median $(\mathrm{IQR})$ micromol/l & $72(55 ; 96)$ \\
\hline $\operatorname{ALT}\left[n^{*}=312\right]$ median $(\mathrm{IQR}) \mathrm{U} / \mathrm{I}$ & $24(16 ; 39)$ \\
\hline GGT $\left[n^{*}=303\right]$ median (IQR) U/I & $44(21 ; 106)$ \\
\hline
\end{tabular}

$n^{*}=$ Number of participants with information available in the medical record

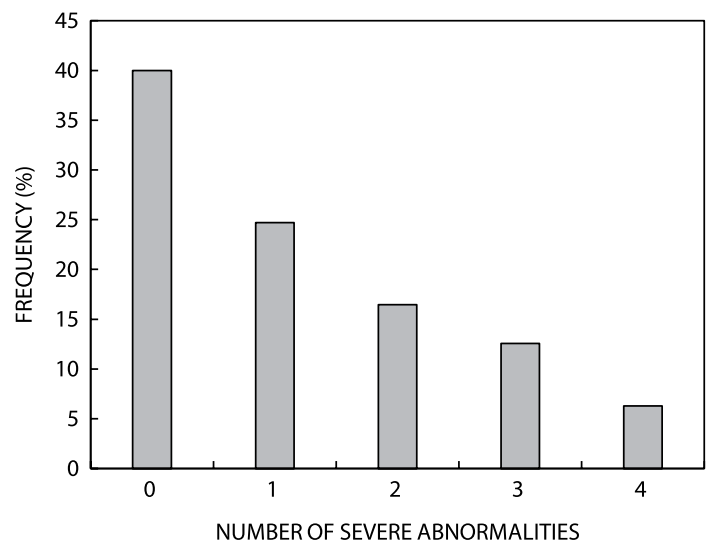

Figure 2: Frequency of severe CSF abnormalities in 255 participants with abnormal CSF analysis severe CSF abnormality defined as: polymorph count $\geq 5 \times 10^{9}$ cells $/$; lymphocyte count $\geq 20 \times 10^{9}$ cells/l; protein $>1.0 \mathrm{~g} / \mathrm{l}$, glucose $<2.2 \mathrm{mmol} / \mathrm{l}$.

Twenty patients (32.2\%) with positive cryptococcal antigen had normal CSF cell counts, with only six having severely abnormal chemistry values.

CSF specimens were not routinely cultured for M. tuberculosis; antituberculosis treatment was initiated when TB meningitis was diagnosed using the results of the differential cell count and biochemistry analysis. Sixty-four (25.1\%) participants were diagnosed with tuberculous meningitis (TBM) after lumbar puncture. The CSF values of these participants differed from other participants with CSF abnormalities: the median lymphocyte count was $35.0 \times 10^{9}\left(\right.$ IQR $\left.18.2 \times 10^{9} ; 96.0\right)$ vs. $3.5 \times 10^{9}($ IQR $0.0 ; 13.0)$ cells/l, protein $1.5($ IQR $1.0 ; 2.6)$ vs. 0.6 (0.4; $1.0) \mathrm{g} / \mathrm{l}$, and glucose 2.1 (IQR 1.3; 2.7$)$ vs. 2.7 (IQR $2.1 ; 3.4) \mathrm{mmol} / \mathrm{I}$ ( $p<0.0001$ for all comparisons).
Table 4: Mortality associations in 205 in-patients with an abnormal CSF analysis.

\begin{tabular}{|l|c|c|}
\hline & OR $(95 \% \mathrm{Cl})$ & $\boldsymbol{p}$-value \\
\hline Age $>35$ years & $2.0(1.1 ; 3.9)$ & 0.02 \\
\hline Female & $0.5(0.2 ; 1.1)$ & 0.06 \\
\hline HIV seropositive & $0.9(0.2 ; 5.8)$ & 1.0 \\
\hline Lymphocyte count $>20$ & $0.4(0.2 ; 0.9)$ & 0.02 \\
\hline Neutrophil count $>20$ & $0.3(0.06 ; 1.1)$ & 0.06 \\
\hline Protein $>1.0 \mathrm{~g} / \mathrm{l}$ & $1.1(0.5 ; 2.0)$ & 0.9 \\
\hline Glucose $<2.2$ & $1.3(0.7 ; 2.5)$ & 0.4 \\
\hline CRAG positive & $1.2(0.6 ; 2.4)$ & 0.7 \\
\hline Haemoglobin $<10 \mathrm{~g} / \mathrm{I}$ & $2.4(1.2 ; 4.8)$ & 0.01 \\
\hline Creatinine $>150 \mu \mathrm{mol} / \mathrm{I}$ & $9.2(3.2 ; 30.3)$ & $<0.0001$ \\
\hline ALT $>50$ IU & $0.2(0.7 ; 4.5)$ & 0.2 \\
\hline GGT $>50$ IU & $2.2(1.1 ; 4.5)$ & 0.02 \\
\hline
\end{tabular}

In the 26 participants with neutrophil predominance, 17 (65\%) had a neutrophil count of $>5 \times 10^{9}$ cells/l, with a median neutrophil count of $90 \times 10^{9}(\mathrm{IQR} 23 ; 411)$ cells/l, protein of $2.2 \mathrm{~g} / \mathrm{l}$ (IQR $0.7 ; 2,6)$ and glucose of $2.2 \mathrm{mmol} / \mathrm{I}(\mathrm{IQR} 0.6 ; 3,3)$. Twenty-five $(96 \%)$ were treated with ceftriaxone.

\section{Culture results}

Thirty-five $(9.1 \%)$ culture results could not be traced. Of the remainder, $310(80.5 \%)$ were culture negative, 35 grew $C$. neoformans $(9.1 \%)$, three grew S. pneumoniae $(0.8 \%)$, one was contaminated $(0.3 \%)$, and one was reported with a laboratory error (0.3\%). One culture-positive specimen with a missing cryptococcal antigen test result grew C. neoformans, and was classified as normal on initial biochemistry and microscopy tests. Fifty-six of the 62 participants with a positive cryptococcal antigen test had a paired culture result of which 32 showed $C$. neoformans (57.1\%).

\section{Associations with inpatient mortality}

Three hundred and five participants were admitted and mortality data was available in 286 (93.8\%). Sixty-eight participants died (23.8\%). The 205 participants who were admitted with an abnormal CSF result were at increased risk of death (OR 3.8 [95\% $\mathrm{Cl} 1.7 ; 9.6] ; p=0.0004)$. The association of clinical and laboratory parameters with mortality are shown in Table 4. Renal insufficiency, anaemia and age $>35$ years were all associated with increased odds of death.

\section{Discussion}

The diagnostic yield from LP was substantial in this study, which evaluated adults presenting with symptoms compatible with meningitis, with two thirds $(65 \%)$ of the participants having abnormal CSF findings and one third (38\%) showing serious abnormality. The majority of participants in this cohort were HIV seropositive, and three quarters were in the age range 13 to 40 years. Neck stiffness, vomiting, photophobia and transaminitis were associated with positive CSF findings, but headache or altered mental state were not associated. Seventy-five percent of the participants were admitted and, of those who were admitted, $26 \%$ died. CSF abnormalities were associated with a more than two-fold increased risk of death, notably in older patients, those with CSF cell counts of $>20$ cells/ $\mu \mathrm{l}$, and those with evidence of underlying disease (specifically anaemia and renal insufficiency). 
Classic symptoms of meningitis in this cohort (neck stiffness, photophobia and vomiting) were associated with an abnormal CSF analysis. However, headache did not reach statistical significance, and an altered mental state was not associated with CSF abnormality, suggesting that clinicians have a low threshold for lumbar puncture in adults with these symptoms.

Lymphocytic meningitis was four times more frequent than neutrophil predominance, with half of these participants treated for TBM. High lymphocyte count, high protein level and low glucose level were significantly higher in those diagnosed with TBM. Cryptococcal meningitis (diagnosed on antigen testing) and presumed tuberculous meningitis were equally common, with these diagnoses made in about half $(49 \%)$ of the participants with CSF abnormality. The percentage of specimens testing cryptococcal antigen positive that subsequently grew $C$. neoformans was low; however, low CSF volume submitted for culture, low fungal burden, undocumented use of secondary fluconazole prophylaxis, and 48-h duration of CSF culture may explain this observation under operational conditions. ${ }^{14}$ The incidence of culture-confirmed bacterial meningitis was also low, possibly due to high rates of empiric use of ceftriaxone in meningitis suspects at primary care clinics before referral to the internal medicine service. ${ }^{15}$ Implementation of CSF bacterial antigen testing may improve the detection of pneumococcal meningitis after antibiotic initiation. ${ }^{16}$

This study has several limitations inherent in the retrospective chart review methodology. Medical records from only $44 \%$ of patients undergoing LP were obtained from the medical registry. Clinical information contained in these records at the time of LP were not collected systematically, resulting in incomplete information and possible bias. Data were not obtained on participants undergoing a second LP after a specific time interval to evaluate for evolving meningitis, which may have led to under-recognition of conditions such as TBM. Finally, data on use of antiretroviral and secondary fluconazole prophylaxis for cryptococcal meningitis by the participants at the time of LP were not collected.

However, this study demonstrates that meningitis, due to tuberculosis and Cryptococcus, are common in this high HIVprevalent public sector institution in KwaZulu-Natal, and that an abnormal CSF analysis is associated with increased mortality in adults with suspected meningitis who were subsequently admitted. A low threshold for LP is appropriate in KwaZulu-Natal. Additional interventions are needed to reduce the high mortality rate in hospitalised patients with CSF abnormalities.

Acknowledgements - We appreciate the assistance of the technicians and management of the National Health Laboratory Service at Edendale Hospital, and Dr Sumayya Hafegee. We also acknowledge the support of management at Edendale Hospital and the KwaZulu-Natal Department of Health.

Conflict of interest - The authors have no conflict of interest to declare.
Funding - This study was conducted as part of an MMed dissertation (ON).

\section{References}

1. Scheld WM1, Koedel U, Nathan B, et al. Pathophysiology of bacterial meningitis: mechanism(s) of neuronal injury. J Infect Dis. 2002 Dec 1;186Suppl 2:S225-33.

2. Luma HN, Tchaleu BC, Ngahane BH, et al. Koulla-Shiro S Tuberculous meningitis: presentation, diagnosis and outcome in HIV-infected patients at the Douala General Hospital, Cameroon: a cross sectional study. AIDS Res Ther. 2013 Jun 11;10(1): 16. https://doi org/10.1186/1742-6405-10-16

3. Jarvis JN, Bicanic T, Loyse A, et al. Determinants of mortality in a combined cohort of 501 patients with HIV-associated Cryptococcal meningitis: implications for improving outcomes. Clin Infect Dis. 2014 Mar;58(5): 736-45. https://doi.org/10.1093/cid/cit794

4. Berhe T, Melkamu Y, Amare A. The pattern and predictors of mortality of HIV/AIDS patients with neurologic manifestation in Ethiopia: a retrospective study. AIDS Res Ther. 2012 Apr;10(9): 11. https://doi. org/10.1186/1742-6405-9-11

5. Veltman JA, Bristow CC, Klausner JD. Meningitis in HIV-positive patients in sub-Saharan Africa: a review. J Int AIDS Soc. 2014 Oct;10(17): 19184.

6. Jarvis JN, Meintjes G, Williams A, et al. Adult meningitis in a setting of high HIV and TB prevalence: findings from 4961 suspected cases. BMC Infect Dis. 2010;10: 67. https://doi.org/10.1186/1471-2334-10-67

7. Marais S, Pepper DJ, Schutz C, et al. Presentation and outcomes of tuberculous meningitis in a high HIV prevalence setting PLOS One. 2011;6(5): e20077.

8. Hiesgen J, Schutte C, Olorunju S, et al. Cryptococcal meningitis in a tertiary hospital in Pretoria, mortality and risk factors - A retrospective cohort study. Int J STD AIDS. 2016 Jun 2;28(5):480-85. pii: 0956462416653559.

9. Longo DL, Ross KL, Tyler KL, et al. Harrison's Principles of Internal Medicine. 18th ed.. New York: McGraw-Hill Professional; 2011.

10. Ruff RL, Dougherty Jr. JH. Complications of lumbar puncture followed by anticoagulation. Stroke. 1981 Nov-Dec;12(6):879-81. https://doi. org/10.1161/01.STR.12.6.879

11. Kuntz KM, Kokmen E, Stevens JC, et al. Post-lumbar puncture headaches: experience in 501 consecutive procedures. Neurology 1992;42: 1884-7. https://doi.org/10.1212/WNL.42.10.1884

12. Williams J, Lye DC, Umapathi T. Diagnostic lumbar puncture: minimizing complications. Intern Med J. 2008 Jul;38(7):587-91. https://doi.org/10.1111/j.1445-5994.2008.01631.x

13. Shisana O, Rehle T, Simbayi LC, et al. South African National HIV Prevalence, Incidence and Behaviour Survey, 2012. Cape Town: HSRC Press; 2014.

14. Boulware DR, Rolfes MA, Rajasingham R, et al. Multisite validation of cryptococcal antigen lateral flow assay and quantification by laser thermal contrast. Emerg Infect Dis. 2014 Jan;20(1): 45-53. https://doi. org/10.3201/eid2001.130906

15. Republic of South Africa. Essential Drugs Programme. Primary Healthcare Standard Treatment Guidelines and Essential Medicines List. 5th ed. Republic of South Africa: National Department of Health; 2014.

16. Boulos A, Fairley D, McKenna J, et al. Evaluation of a rapid antigen test for detection of Streptococcus pneumoniae in cerebrospinal fluid. J Clin Pathol. 2017 May;70(5): 448-450. https://doi.org/10.1136/ jclinpath-2016-204104 